\title{
Nature of social media usage by university students in Sri Lanka: A survey
}

\author{
A.W.V Athukorala \\ Senior Assistant Librarian, Sri Palee Campus, University of Colombo, Sri Lanka
}

\begin{abstract}
Social media is rapidly spreading among the university communities in order to establish a good link between them with technological advances. Today, most Sri Lankan university students use comprehensive electronic devices, such as notebooks, tablets and smartphones, and have easy Internet connectivity. The lack of understanding of its use and its impact on the academic activities of consumers, especially among students at university, is one of the major constraints of current Sri Lankan social media literature. Empirical analysis is important to help understand why and how knowledge and appraisal of social media are useful on the numerous social media platforms. Therefore, objective of this research is to investigate the Nature of social media usage by university students in Sri Lanka. The survey method was used to address the research objectives, the population of the study consisted of students of the Faculty of Arts in the University of Colombo, Sri Lanka. A structural questionnaire was emailed to 500 university students at the faculty of Arts with a brief background to the research. Convenient sampling technique was adopted to administer the research tool (questionnaire) on 500 students $(N=500)$. The response rate was $71.2 \%$ (as $(n=356$ responses complete in all respects were received). The data collected through questionnaire was analyzed through MS-Excel Programmed and the results are presented in tabular cum graphical form. Research found that, the majority of Sri Lankan university students use extensively electronic devices such as smartphones to access to the social media. Study found that, university students use numerous social media resources and apps. Facebook is described by university students as the most frequent and powerful social media site for networking purposes. The variables that affect students on the use of social media based on gender disparities are defined in the following order, based on their importance. In line with priority: male student's, convenience, costs, credibility, time, legal risk, copyright and permanency. For female students these variables are the following: convenience, legal risk, cost, Privacy, credibility, time, and copyright. Research is important in this regard and enlightens the social networks of Sri Lankan students and their impact in the social media of Sri Lanka on education and academic growth. A study reveals that, considering the comparatively new field, social media rapidly spread through university societies to establish a strong relation with technical developments and to propose further research.
\end{abstract}

\section{INTRODUCTION}

$\mathrm{S}$ ocial media has been advanced from Web 2.0 technologies and is a virtual digital product. It's become an important part in the working lives of ordinary internet consumers independent of their devices. In the literature, various meanings and classifications of social media are available, but they typically have common significances. In line with a very common definition: [...] Social media are a community of internet-based apps, which rely on web 2.0, and which allow user generated content to be produced and shared (Kaplan and Haenlein, 2010). The social media featured "[, according to Kaplan and Haenlein (2010) .. .] Joint ventures, websites, content communities, SNS, computer gaming environments and shared virtual worlds." They were further grouped by Lim et al. (2014) "[. . .] seven types of information: email, media sharing, Social networking, smartphone apps, virtual reality and sports, sync and meeting and mash-up applications." However, the advent of social networks created a forum for billions of people to connect with peers and colleagues during the week without geographical limits and restrictions (Friedman et al., 2019).

The role of social media in university student's day today activities have dramatically increased and they have noticeably affected their entire relationships. The incorporation of the social media by students at the university level has modified conventional modes of learning and teaching environment. Today, "YouTube Generation" or "Connected Generation or Gen C" is mainly socially connected. Social media where new knowledge and information are constantly generated in multiple multimedia formats (Barry et al., 2016). Social media have become highly influential in transforming the activities of teaching and learning (Healy, 2015). These places have now become inevitable parts of today's students' lives. Moreover the open, collegial and participative approach to social media allows students to study informally, thus strengthening their adherence to traditional methods of learning (Cao and Hong, 2011). The majority of students are actually interested in multiple websites in the social media. However, as Internet and everyday apps have expanded dramatically, these networks have grown quickly and immersive social networking world (Tan and Yuen, 2018; Hamid et al., 2010). Social media, have provided internet users with substantial interactive resources and played a significant part in increasing their involvement in those processes university students (Doleck and Lajoie, 2018; Giunchiglia et al., 2018; Ali Al-Atwi, 2019).

However, social media can be maintained as having had an impact on numerous aspects in which university students are studying, correspondence and day to day life. In the field of education, social media sites thus played an important part of it. Social media websites have a large Internet share. 
Important decision-making and policy-making for the administration of social networks also requires comprehensive study and research. The objective of this research is to investigate the Nature of social media usage by university students in Sri Lanka. Today, the majority of Sri Lankan university students use extensively electronic devices such as laptops, tablets and smartphones, and have convenient Internet access. The research is significant in this regard and illuminates Sri Lankan students' social networks and effect on educational and academic development in Sri Lanka's social media. However, the researcher in this study do not plan to address in depth their success in education and academics.

The findings of this study are remarkable in that there is no proof or analysis in the related literature surrounding the use and social media by teacher students. In considering the introduction of new technology and technologies into university learning and teaching, the findings of this study are helpful tools for university administers, educational decision makers and creative lecturers in universities, particularly developing countries, and especially Sri Lanka.

\section{LITERATURE REVIEW}

In recent years, social media usage of university students related studies in library and information science have become an attractive topic of study, with much research being done. In developing countries, little research has been carried out, especially in Sri Lanka. The literature in developing countries addressed several areas of university student's interaction with social media in higher education. Nevertheless, in developed countries, implementation and experience in social media use in higher education remain low (Stanciu et al., 2012). Tennakoon et.al (2018) performed a research report on the effect of the use of social media on academic success. The aim of this study was to examine the influence on academic achievements in Sri Lankan state universities of students in social media use. Due to the enormous use of social media by students, the study reported that it was necessary to steam the use of social media for better academic achievements. The results of the research have shown that both determinants have an effect on academic achievement and that the association between social media and academic performance is moderately positive.

Nuskiya and Fathima(2017) have studied that the impact of social media among the university students empirical study based on the South Eastern University of Sri Lanka. The aim of the study was to focus students on the effects of social media. Students of the South East University of Sri Lanka were approached to perform the study. Students have chosen a random sample approach that is stratified. For data analysis, the questions were used and data evaluated by the descriptive and correlation approaches. A research has shown the students' strong dedication to the Facebook and that it has had a positive effect on their academic success and on their skills. The association checked in the same sense, and recorded a positive influence on social media on academic achievement in a state university in Sri Lanka, in Vijayakiruthik and Maheswaranathan (2016). More than one research focuses on the varying results on student success in the social networks.

A students' online social networking survey was carried out by Mustafa and Hamzah (2011). A limit of 40 questionnaires was circulated to participating social media users. It was concluded that students use social media to chat with each other, to stay in contact with old acquaintances, manage and retain friendships for recreation and to acquire information through group discussions. In their research, students even remained on social networking sites for many hours. The research carried out among Kenyan University students was done by Langat (2015) to test the theory of uses and gratifications. Research findings indicated that students also visit social media sites such as WhatS'app and Facebook have an impact on their study behavior. The Ghana analysis has followed the principle of uses and gratifications indicate that WhatsApp adversely affects university students' academic or research patterns in the country regardless of the incentives it brings (Appiah, 2016).

In recent years, some articles has identified the increasing utilizing of social media in universities and highlighted their sensitivity to university students and differences in university culture. In most of these researches, authors have emphasized the possibility to use social media as an aid for learning, information dissemination and communication among university community. Currently, social media has become a life partner on which users share their memories and thoughts with others. Prensky (2012) identified the differences on the use of technological aspects between current university students and students those who were in universities about ten years ago. He mentioned that current improvements of science and technology have uplifted have made their life convenient. He named current university students as digital natives. According to him, these students have been grown up with sophisticated technological equipment's and tools from their childhood. The world education system has profoundly been reshaped by the rapid growth of social media. Many researchers state that by providing them with knowledge and social support and a way to identify and interact with other students, social media will promote the transfer of students from high school to college. Facebook is the most integrated network of these social media tools in the lives of U.S. college students (Hargittai, 2007; Smith, Salaway, \& Caruso, 2009).

On the other hand, Digital Youth Project ${ }^{\mathrm{i}}$ found that in our increasingly technological world, the constant communication that social networking provides is encouraging useful skills. Neither time spent on Facebook nor Facebook checking was significantly associated with either self-esteem, fear of negative social evaluation or social comparison (Muench, et al., 2015). The relationship between times spent on Facebook shows that there was no significant correlation between time spent on Facebook and students' Cumulative Grade Point Average (CGPA) (Lubis, et al., 2012) 
Manca and Ranieri (2016) showed in his study that Italian academic staff members utilize social media applications in teaching and learning practices based on a data sample of university academics with the focusing on social media and perceptions. They further, mentioned that there is a little limitation to use social media due to cultural issues, pedagogical issues or institutional contrasts which are suffering by the academics and discussed the benefits and challenges of social media in universities. Most of the faculty members are well aware about several social media tools and applications and they use them in their personnel life. Even though it was greatly identified the usefulness of social media for teaching and learning activities by the faculty members, they are reluctant to apply these tools in their academic works (Sharma et al., 2016)

Lenhart (2015) indicated that social media is spreading quickly among the university communities to create a good connection between them with technological improvements and suggested to conduct more researches on this, since the field is comparatively new. In this, it is highly needed to give the attention on efficient utilization of social media, issues on social media, and guidelines on proper use, legal issues and impacts to the civil society. He further stated the requirement to establish guidelines for optimum cover of social media and to measure the usefulness of these tools. In universities point of view, these tools can be used to get better opportunities. The influence of social media concept on society is remarkable by providing effective and efficient ways for communication. Falahaha and Rosmalab (2012) discussed the advantages and access for social networking in a broader mind without considering the negative impacts on productivity. Further researchers emphasized that the idea on social networking activities would be possible answers to higher education sector in which most students can be considered as digital natives. Therefore, some universities have understood this novelty and have initiated some actions to use social media for different academic activities, officially or unofficially. They further explained that the applications can be varied according to their individual visions and missions. Further, they have identified a number of social media usages for marketing, communication related works and getting feedbacks. Under communications, it can be used to share complaints, announcements and assignments in higher education institutes. Falahaha and Rosmalab (2012) further mentioned that usage can be depended on the background and attitudes of the user community and policy frameworks of the institute.

In most of researches conducted on the relationship between social media and universities, they have given their total attention for functionalistic approach and have showed the critical role which plays for persistence of the users in universities or higher colleges. It is well noticed that in using social media platforms such as Facebook, it enhances positively transition of the students to colleges by providing a good communication between their peers.
Social media tools and applications such as social network sites, discussion forums and blogs would provide some additional help and information on the way of communication to the students when they transfer from higher schools to university colleges and this scenario would make easier as a social support. 'This scenario had been discussed by Roblyer et al, in 2010 and indicated that social networking sites have very good potential as an aid for education especially in the university level.

\section{Statement of Problem}

A major constraint in current Sri Lankan social media literature is the lack of understanding about its adoption and its effect on the academic activities of users, especially among university students. What or how the social media is used and, the social media have significant links to university students. While discussions are ongoing about the use by students of social media tools to searching for various information, literature on the Sri Lankan university system is not available. Empirical research is critical for students to better understand why and how they are useful in social media information and evaluation through various websites of social media. The findings from such a study help to understand improvements in information literacy education, to facilitate the effective use of students' social media as an information source.

\section{Objectives of the study}

The significance of this study exists in the provision of a better understanding of nature of social media usage among arts stream students with related to gender identity, to investigate the most popular social media tools among university students and to study in what ways help social media for academic activities of the university students. Further this study investigates what factor's concerning when using social media by the university students.

\section{MATERIALS AND METHODS}

In this research, the survey method was used to solve the research objectives, while most of the past studies on social media have built on the method of the case study. Also, the research methodology was designed after a detailed review of past literature to achieve the overall objectives of the current study. To choice respondents, a non-probability purposeful sampling method was used as it is more corporate in professional research, mainly in social science exploration and inherent characteristics such as more affordable, quicker, and more convenient in exploratory research (Bryman\& Bell, 2003). The population of the study consisted of students of the Faculty of Arts in the University of Colombo, Sri Lanka. A structural questionnaire was then used to gather data that was based on multidimensional scaling. The questionnaire was emailed to 500 university students at the faculty of Arts with a brief background to the research. Convenient sampling technique was adopted to administer the research tool (questionnaire) on 500 students $(\mathrm{N}=500)$. The appropriateness 
of this questionnaire was tested through the process of reliability analysis. The response rate was $71.2 \%$ (as $(n=356$ responses complete in all respects were received). The data collected through questionnaire was analyzed through MSExcel Programmed and the results are presented in tabular cum graphical form.

\section{RESULTS AND DISCUSSION}

\section{Use of social media by Gender}

Since one of the objectives of this study is to examine whether the use or effect of social media differs significantly with regard to gender, it is important to extract data with regard to gender as well. $45 \%$ of the female students surveyed use social media, while $55 \%$ of male students use social media, according to the results shown in Figure 1. The findings in Figure: 2 show that $26 \%$ of female students use social media for more than 8 hours a day. $34.70 \%$ of female social media users use social media for 4 to 6 hours a day, while only $18.01 \%$ of female students use social media for less than 2 hours a day. Among male students, most students (26.15\%) use social media for less than 2 hours daily, followed by $20.51 \%$ of male students for 4 to 6 hours using social media. For more than 8 hours per day, only $20 \%$ of male students use social media.

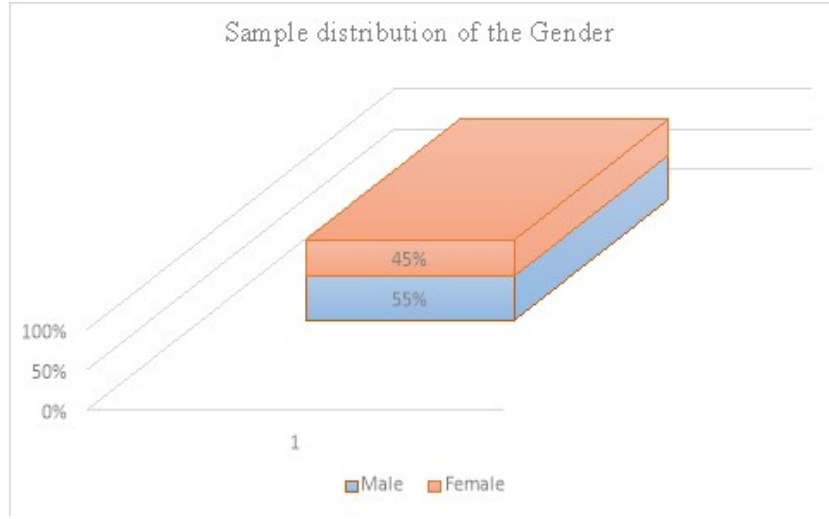

Figure 1: sample by gender

Time spent on social media-sample by gender

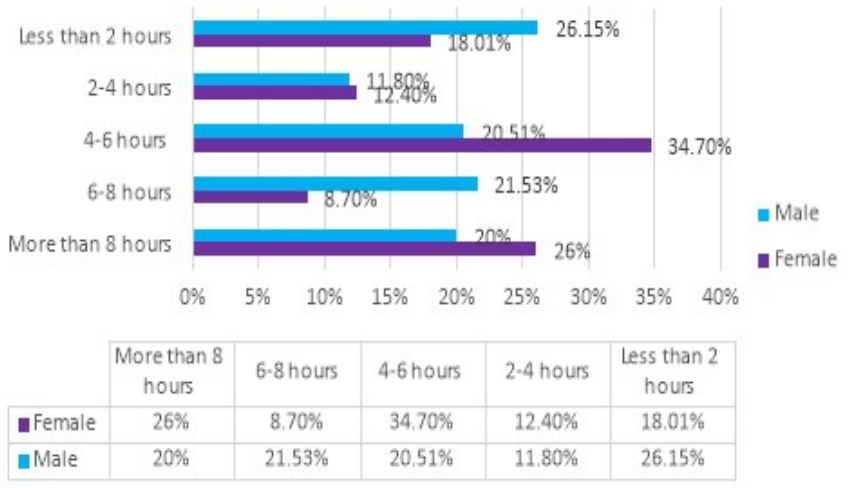

Figure: 2 Time spent on social media -sample by gender
Attitudes of Ease of use social media by the students

A majority of $178=\mathrm{n}$ students $(50 \%)$ suggested that social media networks are "easy" to use in terms of the convenience of accessing social media platforms. Although $144=n(40.5 \%)$ of the students recorded "extremely easy to use" social media websites. This means that it is incredibly convenient to use social networking platforms. This is a good indicator for the subscribers of these networks and perhaps a reason for their success with the masses (Table: 2). As described by the Technology Acceptances Model (TAM) that Perceived Usefulness (PU) and Perceived Ease of Use (PEOU), would be influenced for the adaption of a user to a new technology. PU was defined as "the degree to which person believes that using a particular system would enhance his or her job performance" and PEOU was defined as "the degree to which person believes that using a particular system would be free from effort" by Davis (1989. It means that the factors such as behaviors, intentions and attitudes of the users, usefulness and easiness would influenced directly or indirectly to transfer into a new technology. This model was frequently used in different studies to understand similar scenarios in different technologies (Casalo, 2010; Casalo et al., 2011; Hsu and Lin, 2008; Kwon and Wen, 2010; Steyn et al., 2010; Rauniar et al., 2014).

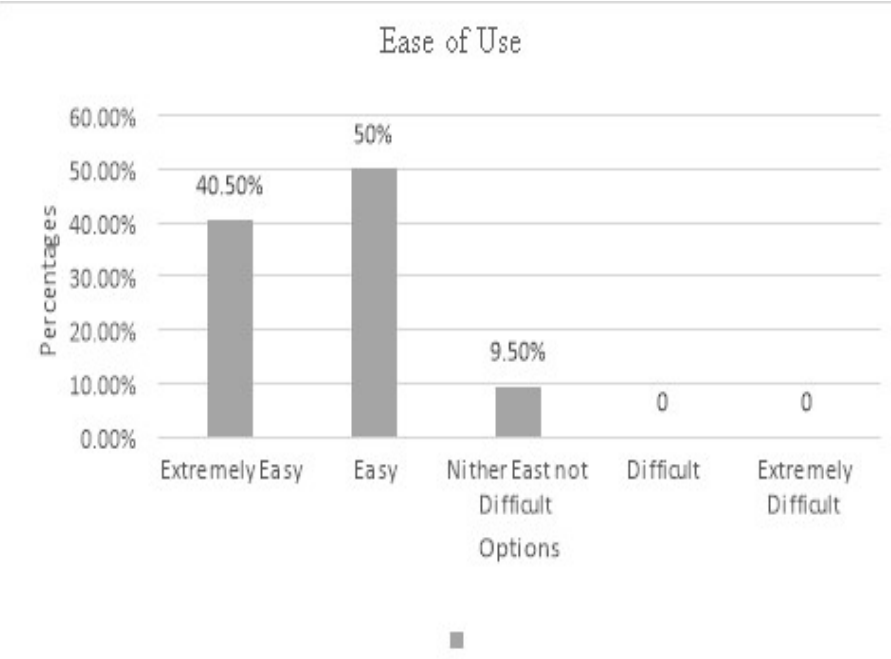

Figure: 3 Ease of use of social media

Factor's concerning when using social media- identify differences by the gender

One of the key aims of this study is to find out the factors that affect university students when using social media, according to the data it reveals that most female students were more concerned about the convenience of social media usage than male students. As a study group, female statements were $54.6 \%$. Although $46.15 \%$ are male. The significance of this fact, however, is that both male and female students were told that their first priority was the convenience of using social media. And $41.02 \%$ are more concerned about the Credibility of social media than female students. Male students are more 
concerned about the time spent on social media than female students. Female students are more concerned about legal risk than male students. Data reveals (figure: 3 ) that when they used social media, both groups of students posed less questions about the copyright factor. According to the findings of the Boyd et al., 2019; Al Jasmi and Awamleh, 2019; Alshuaibi et al., 2018, users of social networking sites, on the other hand, are vulnerable to many various privacy threats, copyrights, simulated reality addiction, child violence, knowledge and identity theft etc.

factor's concern when using social media-sample by gender

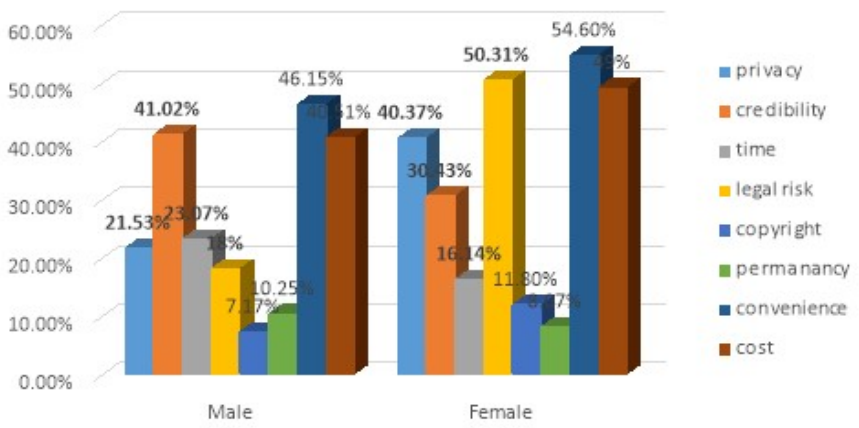

Figure 4: factor's concern when using social media

Types of social media used by university students

In this research, students were asked about the most popular social media used by them. Most of the students in the study mostly used face book as a social media tool, according to the dada, analyzed samples of students $(356=n)$ used the face book. The similar findings of the Fasae and Adegbilero-Iwari (2016) research revealed that Facebook was the students' most popular social media network using for Scholarly reasons. 345 $(=n)$ of the sample studied were using YouTube. According to the research carried out by Barry et al. (2016), Yang and Lee (2020), worldwide university students have been widely used on prominent social media sites such as Facebook and You Tube. Provide valuable and up-to-date knowledge to support high-level student curriculum needs. What's Up $(306=n)$ is the third most popular social media tool among students. LinkedIn $(46=n)$ is used by the smallest number of students. These responses are shown in the figure: 4 .

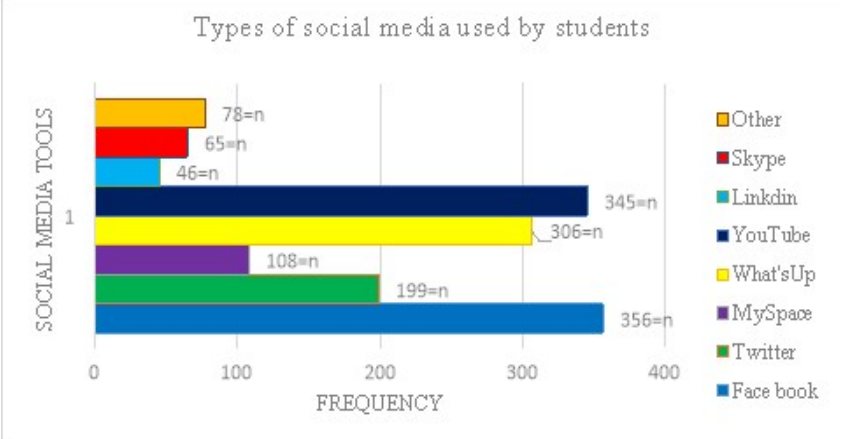

Figure: 5 Types of social media used by students

\section{Access to the Social media tools by the sample}

The data analyzed indicates that the majority of university students $(57 \%)$ use mobile phones or smart phones to access social media. These results are consistent with the findings of Wickramanayake and Muhammad Jika (2018), who have identified cell phones as the most commonly used device for accessing social media networks among university students. However, this finding is not compatible with earlier studies conducted by Singh and Gill (2015) and Stanciu et al. (2012) which indicated that the key resources used to access social media were laptops followed by desktops and cell phones. A large number of students are using tab computers for social media access. A minimum number of students $(7.30 \%)$ use the Note Book for social media use. The following figure: 5, illustrates these responses.

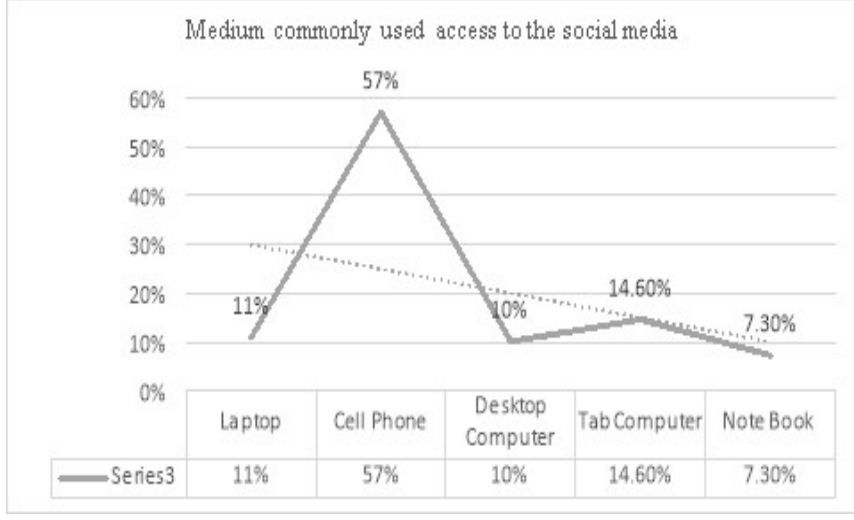

Figure: 6 Medium used access to the social media

\section{Reasons for using social media}

The students at the university were asked to pick the reasons why they use social media websites. According to the results, keeping up with news $(n=324)$ is the main reason for using social media $(\mathrm{n}=312)$, staying in touch with friends $(\mathrm{n}=301)$, establishing connections with academic staff $(n=243)$, are the reasons why university students use social media tools. This has been illustrated in Figure: 7.

\section{Reasons for using social media}

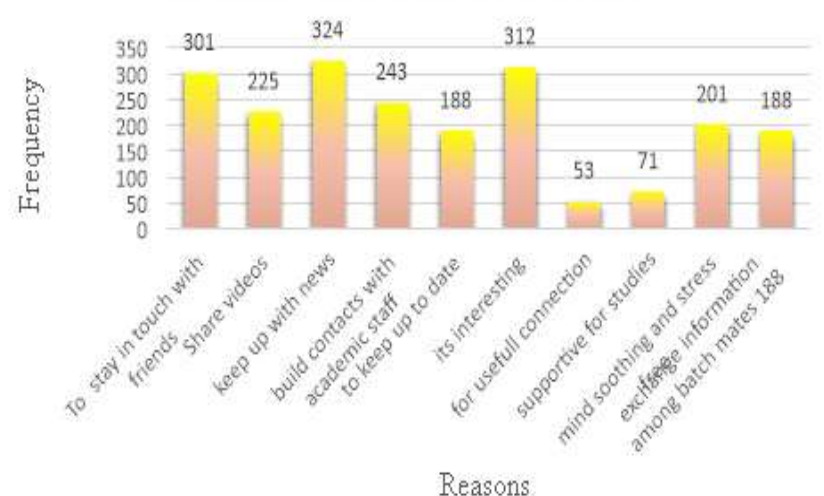

Figure: 7 Reasons for using social media 
With regard to the Challenges and issues related to the use of social media tools, research findings seem to indicate that the main challenge is overload of information ( $87 \%$ ) available at the social media tools. A large proportion of students $(76 \%)$ Social networking sites have been shown to result in addiction of students for social media use. Research Data also indicates that students $(56 \%)$ are subjected to Exposes students to unsuitable content by utilizing social media tools. This is shown in the following figure. However, Mohamed and Sumitha (2011) and Hamade (2013) have stated that "unstable security and privacy issues" and "fear of misuse of personal information"

Great barriers, though Fasae and Adegbilero-Iwari (2016) have revealed that low internet access and unreliable power connections are the key barriers faced by university students when they using social media tools.

\section{challengesIssues faced by students when using social media}

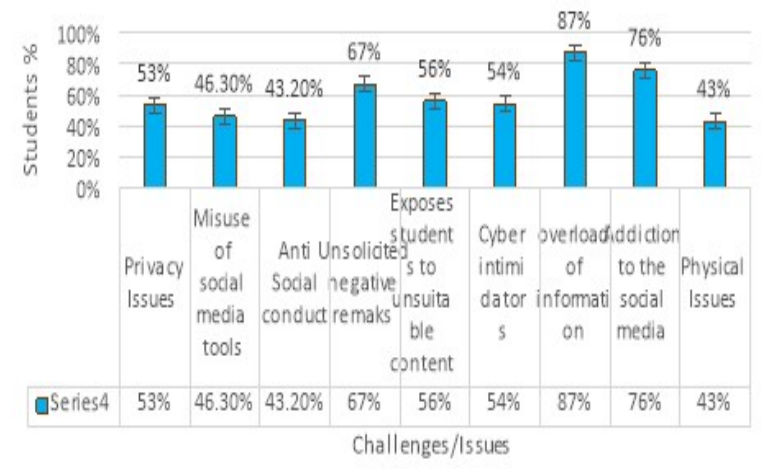

Figure: 8 Challenges faced by students when using social media

\section{CONCLUSION}

The factors that influence students based on gender differences to use social media are described in the following order based on their significance. According in order to the priority: Male student', convenience, cost, credibility, time, legal risk, permanency and copyright. These variables are in the following order for female students: convenience, legal risk, cost, privacy, credibility, time, copyright, and permanency. Among female students, the privacy concern is in higher ranked than male students. However, regardless of the influence of gender variable, convenience is always listed as top concerns, and it is the most important influencing factors for both group of students. On the other hand, they are not highly concerned with the permanence and copyright. In contrast, in addition to copyright and permanency factors, both male and female students pay more attention to cost factor than other factors. The study found that social media was a very common means of education, entertainment and networking among university students. A further research found out that the bulk of people used cell phones to enter social media.
University students use different social media tools and applications for their day to day activities. Facebook is identified as the highest usage, most common and influential social media platform among university students for communicating purposes by this research. As the study identified that Facebook is popular among university students, it can be used for academic works and to share academic resources among the students in higher education institutes in Sri Lanka. Finally, in this study suggested creating Facebook groups between students and teachers which makes comfortable learning environment. A study suggests that social media quickly spread among university communities to create a good link with technological advances and suggested more research, given the relatively new field. This is the key focus of the social media efficiency, social media issues and guidelines on the correct use of social media, legal issues and the effects of civil society.

\section{REFERENCES}

[1] Ali Al-Atwi, A. (2019), "The effect of social network ties on performance: a moderated mediation model", International Journal of Productivity and Performance Management, available at: https://doi.org/10.1108/IJPPM-01-2019-0038

[2] Alwagait, E., Shahzad, B. and Alim, S. (2015), "Impact of social media usage on students' academic performance in Saudi Arabia", Computers in Human Behavior, Vol. 51, pp. 1092-1097.

[3] Alshuaibi, M.S.I., Alshuaibi, A.S.I., Shamsudin, F.M. and Arshad, D.A. (2018), "Use of social media, student engagement, and academic performance of business students in Malaysia", International Journal of Educational Management, Vol. 32, pp. 625-640

[4] Appiah, M.K. (2016), "Influence of WhatsApp on study habit of university students in Ghana", International Journal of Research in Education and Social Sciences, Vol. 6 No. 3, pp. 280-292.

[5] Barry, D.S., Marzouk, F., Chulak-Oglu, K., Bennett, D., Tierney, P. and O'Keeffe, G.W. (2016), "Anatomy education for the YouTube generation", Anatomical Sciences Education, Vol. 9 No. 1, pp. 90-96, doi: 10.1002/ ase.1550.

[6] Bryman, A \& Bell, E. (2003). Business research methods. New York: Oxford University Press.

[7] Doleck, T. and Lajoie, S. (2018), "Social networking and academic performance: a review", Education and Information, Technologies, Vol. 23No. 1, pp. 435-465.

[8] Falahah and Rosmala.D (2012) .Study on social networking usage in higher education environment, the 3 rd international conference on e-learning, ICEL (2011) 23-24 November. Available at www.sciencedirect.com

[9] Fasae, J.K. and Adegbilero-Iwari, I. (2016), "Use of social media by science students in public universities in southwest Nigeria", The Electronic Library, Vol. 34 No. 2, pp. 213-222, doi: 10.1108/EL-11-2014-0205.

[10] Friedman, K.A., Herman, S.W. and Fornari, A. (2019), "Medical education using minimal technology: achieving professional development", Medical Education Online, Vol. 24 No. 1, p. 1622365, doi: 10.1080/ 10872981.2019.1622365

[11] Giunchiglia, F., Zeni, M., Gobbi, E., Bignotti, E. and Bison, I. (2018), "Mobile social media usage and academic performance", Computers in Human Behavior, Vol. 82, pp. 177-185.

[12] Hamade, S.N. (2013), "Perception and use of social networking sites among university students", Library Review, Vol. 62 Nos 6/7, pp. 388-397.

[13] Healy, F. (2015), "Technology and the changing education landscape", available at: www.leadscon.com/technologychangingeducation-landscape/ 
[14] Kaplan, A. M., \& Haenlein, M. (2010). Users of the world, unite! The challenges and opportunities of Social Media. Business Horizons, 53, 59-68

[15] Langat, A.C. (2015), "Influence of social media on study habits of undergraduate students in Kenyan universities", International Journal of Novel Research in Humanity and Social Sciences, Vol. 2 No. 4 , pp. 42-55.

[16] Lenhart, A (2015).Teens, Technology and Friendships: Video games, social media and mobile phones play an integral role in how teens meet and interact with friends. Internet, science and tech Pew Research Centre

[17] Manca, S. and Ranieri, M. (2016).Facebook and the others. Potential and obstacles of social media for teaching in higher education. Computers and Education, 95, pp. 216-230.

[18] Mohamed, H.K. and Sumitha, E. (2011), "Perception and use of social networking sites by the students of Calicut University", DESIDOC Journal of Library \& Information Technology, Vol. 31 No. 4, pp. 295-301.

[19] Mustafa, S.E. and Hamzah, A. (2011), "Online social networking: a new form of social interaction", International Journal of Social Science and Humanity, Vol. 1 No. 2, pp. 96-103.

[20] Prensky, M. (2012), From Digital Natives to Digital Wisdom Introduction:HopefulEssays for 21st Century Education;Corwin.pp.1-9.

[21] Sharma, S.K; Joshi, A and Sharma, H. (2016).A multi-analytical approach to predict the Facebook usage in higher education. Computers in Human Behavior, 55, pp.340-353.

[22] Shittu, A.T., Basha, K.M., AbdulRahman, N.S.N. and Ahmad, T.B.T. (2011), "Investigating students' attitude and intention to use social software in higher institution of learning in Malaysia", Multicultural Education\& Technology Journal, Vol. 5 No. 3, pp. 194-208.

[23] Singh, K.P. and Gill, M.S. (2015), "Role and users' approach to social networking sites (SNSs): a study of universities of North India", The Electronic Library, Vol. 33 No. 1, pp. 19-34.

[24] Vijayakiruthik. S 1 and Maheswaranathan. S2 1,2 Department of Economics, Eastern University of Sri Lank

[25] Wickramanayake, L. and Muhammad Jika, S.M. (2018), "Social media use by undergraduate students of education in Nigeria: a survey", The Electronic Library, Vol. 36 No. 1, pp. 21-37, doi: 10.1108/EL-01-2017-0023

[26] Yang, C.C. and Lee, Y. (2020), "Interactants and activities on Facebook, Instagram, and twitter: associations between social media use and social adjustment to college", Applied Developmental Science, Vol. 24 No. 1, pp. 62-78, doi: 10.1080/10888691.2018.1440233. 